\title{
Management of chronic hepatitis B in special populations
}

\author{
Elsaid Elbadrawy ${ }^{1}$, Tarik Zaher ${ }^{1}$, Eman Mousa ${ }^{2 *}$, Mostafa Elshenaway ${ }^{3}$, Ahmed \\ Alhawarey $^{3}$, Mohamed Abdel-Aziz ${ }^{3}$, Hoda Elgamal ${ }^{3}$. \\ ${ }^{1}$ Tropical Medicine dept., Zagazig Univ., Zagazig, Egypt; ${ }^{2}$ Faculty of Dentistry, Mansoura Univ, Mansoura, \\ Egypt; ${ }^{3}$ Tropical Medicine dept., Mansoura Univ, Mansoura, Egypt \\ *eman.nasser.mousa@gmail.com
}

Received: 11-1-2020

Accepted: 28-2-2020

\begin{abstract}
Hepatitis B infection is an international healthcare problem, particularly in developing areas. The hepatitis B virus (HBV) is frequently transmitted via body fluids such as blood, semen, and vaginal secretions. The majority of adults infected with the virus recover, however 5\%-10\% are not capable to clear the virus and become chronically infected. The principal treatment goals for patients with hepatitis $\mathrm{B}$ infection are to prevent progression of the liver disease to cirrhosis or hepatocellular carcinoma. The effective nucleos(t)ide analogs (NAs) against hepatitis $\mathrm{B}$ virus (HBV) has improved the outcome of patients with chronic hepatitis B (CHB). Special populations infected with chronic HBV include those with decompensated cirrhosis, organ transplantation, pregnancy, extrahepatic manifestations, immunosuppressive-chemotherapy, co-infections (HIV-HCV-HDV), renal failure, hepatitis B virus infection in children/adolescents and dental practice. These populations vary in their natural history and risk of liver-related complications, the indications for anti-HBV treatment in addition to the recommendations concerning the HBV drugs used, time of therapy and expected endpoints. The aim of this review is to summarize the information on the relevance and treatment of $\mathrm{HBV}$ infection in such special populations.
\end{abstract}

Keywords. Hepatitis B virus, Cirrhosis, Pregnancy, HBV-HCV coinfection, HBV Reactivation, Nucleos(t)ide analogues and dental practice.

\section{Introduction}

Hepatitis B virus (HBV) infection is a major public health problem worldwide. $\mathrm{HBV}$ is a member of the hepadnaviridae family (a small DNA viruses) that replicates through an RNA intermediate and can integrate into the host genome ${ }^{1}$. The Eastern Mediterranean region has a high prevalence (3.3\%); while it is lower in the South-East Asian (2.0\%) and European regions (1.6\%) and is lowest in the North and South American regions $(0.7 \%)^{2}$. The key serological marker of acute and chronic hepatitis $\mathrm{B}$ is the detection of HBsAg in serum. However, several other HBV serological markers are clinically useful in HBV infection. For example, in patients with clinical recovery from $\mathrm{HBV}$ infection, anti$\mathrm{HBs}$ and hepatitis $\mathrm{B}$ core antigen $(\mathrm{HBcAg}$; anti$\mathrm{HBc}$ ) may be detectable ${ }^{1}$. In addition to serum tests, an assessment of the fibrosis and cirrhosis status in patients with chronic HBV infection is also important for disease prognostication and management. Nowadays, many non-invasive markers were available for assessment of liver fibrosis in patients with chronic HBV infection, for example, APRI and FIB-4 could reliably differentiate significant fibrosis, advanced fibrosis and cirrhosis ${ }^{3}$. The aim of HBV treatment is to decrease the risk of progression to cirrhosis- and liver-related complications mostly hepatocellular carcinoma.

\section{Management of Chronic HBV in Special Populations}

\section{Cirrhosis}

Patients with any detectable HBV DNA and compensated or decompensated cirrhosis should be treated irrespective to ALT values ${ }^{4}$. Nucleos(t)ide analogues (NAs) are the best treatment option. PegIFNa is contraindicated in patients with decompensated liver disease ${ }^{\mathbf{5 , 6}}$. Entecavir (ETV) or tenofovir disoproxil fumarate (TDF) are recommended as the ideal first-line drugs in patients with decompensated cirrhosis $^{7}$. Both have been shown to be effective and well tolerated ${ }^{8,9}$. Despite an overall high safety profile, lactic acidosis remain a rare but serious side effect with the use of any NA and is likely a higher risk in patients with decompensated cirrh-osis ${ }^{10}$. Patients with decompensated cirrhosis should also be referred for liver transplantation, but treat-ment with NAs must be started as early as possible for rapid and complete viral suppression. The main goal of NAs treatment in patients with decompensated liver disease is to achieve clinically compensated disease and avoid liver transplantation ${ }^{11}$. All patients with decompensated disease should receive antiviral treatment for life. However, the risk of developing HCC remains high in this specific group, consequently careful long-term HCC monitoring must be performed ${ }^{12}$. 


\section{Organ transplantation}

The entire HBsAg-positive candidates for liver transplantation should be treated with a NA to obtain undetectable HBV DNA. NA therapy is continued following liver transplantation in combination with HBV immunoglobulin (HBIG) to prevent graft infection. A short course of HBIG or prophylaxis with NA alone can be considered in selected patients with a low risk of recurrent HBV. On the other hand, a lifelong combination of NA and HBIG should be given to patients who are at a high risk of HBV recurrence, as well as to patients who are HBV DNA positive at liver transplantation, $\mathrm{HBeAg}$ positive, have HCC, and HDV or HIV co-infection ${ }^{4}$. Therapy should be continued post-transplant indefinitely, regardless of HBeAg or HBV DNA status. At present, combination HBIG and NA (TDF or ETV) therapy is the standard of care for prevention of HBV infection in many transplant programs. This combination prevents $\mathrm{HBV}$ infection in $\geq 95 \%$ of transplant recipients ${ }^{13}$. Recurrent $\mathrm{HBV}$ after transplant is an infrequent occurrence with the success of modern HBV prophylaxis. Nearly, less than $5 \%$ of patients are reported to develop recurrence and most cases are managed by use of long-term NA therapy ${ }^{14}$. The diagnosis of HBV in non-hepatic solid organ transplant basis on the same assays used in the nontransplant population ${ }^{15}$. The AASLD guidance statements for management of hepatitis B in non-liver solid organ transplant recipients recommend that, all transplant recipients of extrahepatic organs should be evaluated for HBV infection and immunity with (HBsAg, anti-HBc, and anti-HBs). Patients without anti-HBs should receive hepatitis B vacci-nation pretransplant. All HBsAg-positive organ transplant recipients should receive lifelong antiviral therapy to prevent or treat reactivation of HBV after transplantation. Tenofovir alafenamide (TAF), TDF and entecavir are best antiviral drugs because of the low rate of resistance with long-term use. HBs Ag-negative, anti-HBc-positive non-liver recipients should be monitored for reactivation. Moreover, any untreated non-liver recipient undergoing monitoring for reactivation should have ALT and HBV DNA measurements every 3 months for the first year post transplant and after receipt of $\mathrm{T}$ cell-depleting therapies, such as antithymocyte globulin ${ }^{7}$.

\section{Pregnancy}

In female of childbearing age who plan to become pregnant, the decision to begin therapy needs to take into account the potential impact on the fetus. For pregnant patients without active or advanced chronic HBV infection, antiviral therapy can be postpone ${ }^{7}$. In a woman of childbearing age with advanced fibrosis or cirrhosis who considered pregnancy, Peg-IFNa should be the first-line treatment because it is the only finite short-term treatment with a chance of an off-therapy sustained virological response ${ }^{4,16}$. It should be noted that contraception is necessary during treatment ${ }^{7}$. The majority of guidelines advise starting the antivirals during the third trimester in pregnant females, which appears to be safe and effective in decreasing mother-to-child transmission (MTCT) ${ }^{7}$. Antivirals drugs that are considered safe in pregnancy are lamivudine (LAM), telbivudine (TBV), and tenofovir disoproxil fumarate (TDF) ${ }^{\mathbf{1 7}}$. However, TDF is now considered to be the best option. According to EASL guidelines, if NA therapy is given only for prevention of MTCT, it may be stopped within the first 3 months after delivery. If the anti-HBV therapy is discontinued during pregnancy or early after delivery, women need to be strictly monitored for the risk of hepatic flares ${ }^{4}$. Administration of hepatitis immune globulin and HBV vaccination within 12hours of birth and completion of the HBV vaccine series is $85-95 \%$ effective in preventing chronic HBV in newborns of HBsAg-positive mothers ${ }^{16,18}$. Though HBsAg can be detected in breast milk, the current World Health Organization recommended that, there is no additional risk of HBV transmission through breastfeeding, even in the absence of immunization. However, breastfeeding should be avoided in the presence of cracked or bleeding nipples as this would cause mixing of serous exudates with breast milk and can potentially lead to transmission of hepatitis B.

\section{Extrahepatic manifestations}

Extrahepatic manifestations of HBV infection are not unusual and should not be ignored. One of them is the pre-icteric serum sickness syndrome, which disappears when icterus and liver lesions occur. Polyarteritis nodosa is characteristic of extrahepatic manifestations with potential severity and multiform aspects involving mainly vasculitis with musculoskeletal, kidney, mesenteric, and neurologic manifestations. After long being life-threatening, it has become most often curable by newer potent nucleoside analogues combined, according to the severity with steroid and possible plasma excha-nges ${ }^{19}$.

\section{Immunosuppressive-chemotherapy}

It is essential to screen all the candidate patients prior to immunosuppressive therapy or chemotherapy, because most of the chronic HBV-infected patients are not aware of their infection. Guidelines from the international liver society recommended mandatory screening for serum $\mathrm{HBsAg}$ and anti-HBc before starting any immunosuppression ${ }^{20}$. The risk of HBV reactivation in patients under immunosuppressant therapies can be reduced markedly by HBV antiviral 
prophylaxis. Receiving HBV antiviral agents in cases of immunosuppressive therapy or chemotherapy was demonstrated to be effective in decreasing the risk of HBV reactivation. Prophylaxis also could be started before starting therapy. Prophylaxis should continue for at least 6 months after termination of immunosuppressive drugs. Additionally, it has been recommended that, antiviral prophylaxis must continue after 12 months after ending of rituximab therapy and only discontinued if the underlying disease is in remission ${ }^{21}$. Early withdrawal of prophylactic treatment must be strongly avoided in cases under hematopoietic stem cell transplant, even in the presence of complete remission therefore, prophylaxis longer than 24 months was recommended for these patients ${ }^{22}$. HBV re-activations may occur under immunosuppression. This reactivation may present with different manifestations ranging from asymptomatic to a severe and fatal clinical appearance and may result in the stoppage of immunosuppression results in increased morbidity and mortality induced by the primary disease. So, starting antiviral prophylaxis before immunosuppressive therapy or chemotherapy can be lifesaving ${ }^{23}$. There is high resistance to lamivudine (LAM) with a risk of reactivation following more than 6 months from the cessation of immunosuppressive therapy or chemotherapy. It is recommended that referenced HBV antiviral agents, such as entecavir (ETV) and TNV should be used in therapies that need long-term prophylaxis ${ }^{24}$.

\section{Acute hepatitis B}

Adult patients with acute hepatitis B recover clinically and virologically with seroconversion to anti-HBs without antiviral therapy in greater than $95 \%$ of patients. Thus, the main goal of potential treatment in these patients should be the prevention of acute or subacute liver failure ${ }^{25}$. Early antiviral therapy with highly potent NAs can prevent progression to acute liver failure and liver transplantation or mortality. Therefore, only patients with severe acute hepatitis $\mathrm{B}$, characterized by coagulopathy (INR >1.5) or a protracted course (i.e., persistent symptoms or marked jaundice for $>4$ weeks) or signs of acute liver failure should be treated with NA and considered for liver transplantation ${ }^{\mathbf{4 , 2 6}}$.

\section{Hepatitis $B$ infection and kidney diseases}

HBV patients with chronic kidney disease (CKD) requires special management, a multidisciplinary approach and thorough renal monitoring. The administration of NAs has increased the prognosis of patients with CKD dramatically and has prevented the $\mathrm{HBV}$ recurrence after $\mathrm{RT}^{27}$. In patients with $\mathrm{CKD}, \mathrm{ETV}$ is considered the first choice, regardless of viremia. Telbivudine is the best option when patients present low creatinine clearance and low viremia levels. Telbivudine has been proved efficacious in causing eGFR elevation in CHB patients with high risk of renal impairment ${ }^{28,29}$. TDF is the best choice during lamivudine resistance ${ }^{30}$, but concerns exist regarding TDF use, because few cases of ostemalacia and Fanconi syndrome have been documented ${ }^{31}$. Physicians should be alert about these side effects, and monitor patients closely who are under these medications, especially when creatinine clearance is below $50 \mathrm{~mL} / \mathrm{min}$.

\section{Co-infections}

Co-infection with chronic hepatitis B infection is commonly seen in patients with human immunodeficiency virus (HIV) due to shared routes of transmission $^{32}$. All patients with HBV and HIV coinfection should start antiretroviral therapy for HIV whatever the CD4 cell count. Cornerstones of therapy are oral nucleoside/nucleotide reverse transcriptase inhibitors (NRTI) with dual HBV and HIV anti-viral effect, including tenofovir disoproxil fumurate or tenofovir alafenamide (TAF), with emtricitabine (FTC) or LMV. The rationale for dual HBV therapy is to prevent development of resistance $^{33}$. HBV and HDV co-infected patients with compensated liver disease can usually be treated with Peg-IFNa. Peg-IFN- $\alpha$ for 12 months is the recommended therapy for those with elevated HDV RNA levels and ALT elevation. NA therapy can be used in this group with ongoing HBV DNA replication with HBV DNA > $2000 \mathrm{IU} / \mathrm{ml}^{4}$. In patients with elevated ALT levels, measurement of HBV DNA and HDV RNA will allow determination of the need for NA alone, peg-IFN alone, or combination therapy. NAs have no efficacy against HDV infection. They are not recommended in patients with suppressed or low HBV replication except patients with cirrhosis. HBV DNA levels may change over time, including during treatment of HDV infection. Treatment with preferred NAs (entecavir, TDF, TAF) is recommended if the HBV DNA levels become elevated ${ }^{7}$. In HBV-HCV coinfected patients, the viral activity responsible for liver disease can be determined by measuring HCV RNA and HBV DNA levels. If HCV RNA is detectable, treatment of HCV should be undertaken ${ }^{7}$. If HBV DNA is detectable, treatment is determined by the HBV DNA and ALT levels ${ }^{34}$. Treatment of $\mathrm{HCV}$ with directly acting antivirals (DAAs) may cause HBV reactivation in patients with HBV-HCV co-infection. Thus, NA therapy is recommended not only in patients fulfilling the standard indications for $\mathrm{HBV}$ treatment but in all $\mathrm{HBsAg}$-positive cases. NA should be given during DAAs and until 12 weeks after the end of DAAs therapy ${ }^{7}$. HBsAgnegative, anti-HBc-positive patients receiving DAAs therapy should be monitored and tested for $\mathrm{HBV}$ reactivation in the presence of elevated $\mathrm{ALT}^{4}$. 


\section{Hepatitis $B$ virus infection in children/adolescents} Children have most commonly been infected by their mother (vertical transmission) or at a young age (horizontal transmission). In patients infected by their mothers at an early age, the risk of developing chronic hepatitis $\mathrm{B}$ is around $95 \%{ }^{35}$. The proportion of patients with spontaneous $\mathrm{HBeAg}$ seroconversion is significantly lower in children, who are most often pre- or perinatally infected. Treatment should be considered in patients with repeated ALT elevations over a period of at least 1 year. This applies mainly to children and adolescents with remaining $\mathrm{HBeAg}$. It may also be relevant to a few patients who have seroconverted to anti-HBe, a liver biopsy should be considered to assess necroinflammation and fibrosis before determining the treatment regimen. Treatment may be considered when the histological classification shows at least moderate or mild inflammation, with at least moderate fibrosis $(>\mathrm{F} 2)$. Treatment can be given either in the form of peg-IFN or NA and is currently indicated only for patients with transaminase elevation or histological signs of inflammation. Combination therapy with peg-IFN and NA in patients with normal transaminase levels should be awaited before such treatment can be used routinely $^{36}$. Peg-IFN alpha-2a was given at the dose $100-\mu \mathrm{g} / \mathrm{m}^{2}$ per week during 1 year results in $\mathrm{HBeAg}$ serocnversion rate of 25 vs $6 \%$ for placebo treated patients ${ }^{37}$. Among the NAs, ETV is approved for children from 2-years of age, at a dose of $0.015-\mathrm{mg} / \mathrm{kg}$ daily, max. $0.5-\mathrm{mg} / \mathrm{day}^{38}$. Both TDF and TAF (10-mg) oral-once/day are approved for children from 12-years of age. LAM, at a dose of $3-\mathrm{mg} / \mathrm{kg}$ daily, max. $100-\mathrm{mg} /$ day is approved from infancy. The choice is to either give a timelimited peg-IFN treatment with expected sideeffects, or to give NA for several years, where the chief rule is to treat at least 1 year after $\mathrm{HBeAg}$ seroconversion. Even though treatment with interferon is difficult, due to side-effects, treatment interruptions are rare. Except for the side-effects described in adults, Peg-IFN treatment often leads to anorexia and weight loss and risk of affecting growth, and should therefore be avoided before the age of three and during puberty. Hypothyroidism is a more common side effect in children than in adults (around $10 \%)^{\mathbf{3 9}}$. Seroconversion of $\mathrm{HBeAg}$ to anti-HBe, as well as normalization of liver function can be expected in approximately $30 \%$ of the patients treated with interferon. The results are comparable to those observed in NA treatment. HBsAg disappears more often in patients treated with interferon than in untreated patients ${ }^{37}$. Longterm benefits regarding the development of cirrhosis and HCC cannot yet be evaluated due to limited follow-up times.

\section{Hepatitis $B$ prevention and management in dental} practice

A dentist can play the most important role in the prevention of hepatitis by considering each and every patient as a potential carrier of hepatitis. In a dental office, infections can be expedited through numerous routes including, direct or indirect contact with blood, oral fluids, droplet splatter, aerosols. HBV infection is the most important infectious occupational hazard in the dental profession ${ }^{40}$. Patients with periodontal disease showed higher detectability rate of $\mathrm{HBsAg}$, anti-HBc, anti-HCV, or both anti$\mathrm{HCV}$ and anti-HBc in whole unstimulated saliva than the controls ${ }^{41}$. To decrease the burden of hepatitis in dental health care workers, it is recommended that the dental professionals should receive immunization against hepatitis virus and should use individual protective equipments such as gloves, head caps, masks, etc ${ }^{42}$.A dentist who is HBsAg-positive with HBV DNA > $2000 \mathrm{IU} / \mathrm{mL}$ may be treated with a potent NA to obtain an undetectable or at least $<2000 \mathrm{IU} / \mathrm{mL}$ HBV DNA levels before resuming exposure-prone procedures ${ }^{4}$. It is of great value for the dentist to know that, HBV patient still carry the virus up to 3 months after the symptoms have disappeared. Any patient with a recent history of hepatitis B should be treated for dental emergency problems only ${ }^{43}$.

\section{References}

[1] Mohamed A, Reda E, Mohamed M, Nasser M. Hepatitis B virus: Update in management. Medical J. of Viral Hepatitis. 2019; 3 (2): 49-56

[2] World Health Organization. Global Hepatitis Report. WHO, Geneva. 2017.

[3] Shiha G, Mousa N, Salah M, Soliman R, Abed $\mathrm{S}$, Elbasiony $\mathrm{M}$, et al. Noninvasive markers for staging fibrosis in chronic hepatitis B patients. Medical Journal of Viral Hepatitis. 2018; 2 (2): 17-23

[4] European Association for the study of the Liver. (EASL) clinical practice guidelines: Mana-gement of chronic hepatitis B virus infect-ion. J. Hepatol. 2017; 67: 370- 398.

[5] Miquel M, Núñez Ó, Trapero-Marugán M, DíazSánchez A, Jiménez M, Arenas J, et al. Efficacy and safety of entecavir and/or tenofovir in hepatitis B compensated and decompensated cirrhotic patients in clinical practice. Ann Hepatol. 2013; 12: 205-212.

[6] Cholongitas E, Papatheodoridis GV, Goulis J, Vlachogiannakos J, Karatapanis S, Ketikoglou $\mathrm{J}$, et al. The impact of newer nucleos(t)ide analogues on patients with hepatitis B decompensated cirrhosis. Ann Gastroenterol. 2015; 28: 109-117. 
[7] Terrault N, Lok A, McMahon B, Chang $\mathrm{K}$, Hwang J, Jonas M. Update on prevention, diagnosis, and treatment of chronic hepatitis B: AASLD 2018 hepatitis B guidance. Hepatology. 2018; 67 (4): 1560-1599.

[8] Wang F, Li B, Li Y, Liu H, Qu W, Xu H, et al. Entecavir for Patients with Hepatitis B Decompensated Cirrhosis in China: A meta-analysis. Sci Rep. 2016; 6: doi: 10.1038/srep32722.

[9] Zhang X, Liu L, Zhang M, Gao S, Du Y, An $\mathrm{Y}$, et al. The efficacy and safety of entecavir in patients with chronic hepatitis B-associated liver failure: A meta-analysis. Ann Hepatol. 2015; 14: 150-160

[10]Lange C, Bojunga J, Hofmann W, Wunder K, Mihm U, Zeuzem S, et al. Severe lactic acidosis during treatment of chronic hepatitis $B$ with entecavir in patients with impaired liver function. Hepatology. 2009; 50: 2001-2006.

[11] Vlachogiannakos, J, Papatheodoridis, G. Hepatocellular carcinoma in chronic hepatitis B patients under antiviral therapy. World J. Gastroenterol. 2013; 19: 8822-8830.

[12]Centers for Disease Control and Prevention (CDC). Updated CDC recommendations for the management of hepatitis $\mathrm{B}$ virus infected health $\square$ care providers and students. MMWR Recomm Rep. 2012; 61: 1-12.

[13] Cholongitas E, Papatheodoridis G. High genetic barrier nucleos(t)ide analogue(s) for prophylaxis from hepatitis $B$ virus recurrence after liver transplantation: A systematic review. Am J. Transpl. 2013; 13 (2): 353-362.

[14] Coffin C, Terrault N. Management of hepatitis B in liver transplant recipients. J. Viral Hepat. 2007; 14 (1): 37-44.

[15]Lok A, McMahon B. Chronic hepatitis B: Update 2009. Hepatology. 2009; 50: 661-662.

[16]Chen H, Lee C, Chang C, Ni Y, Shyu M, Chen $\mathrm{S}$, et al. Efficacy of maternal tenofovir disoproxil fumarate in interrupting mother-toinfant transmission of hepatitis B virus. Hepatology. 2015; 62: 375-386.

[17] Xu W, Cui Y, Wang L, Yang H, Liang Z, Li $\mathrm{X}$, et al. Lamivudine in late pregnancy to prevent perinatal transmission of hepatitis B virus infection: A multicentre, randomized, double-blind, placebo-controlled study. J. Viral Hepat. 2009; 16: 94-103.

[18]Chang E, Sue E, Zola J, So S. 3 for life: A model pilot program to prevent hepatitis B virus infection and liver cancer in Asian and Pacific islander Americans. Am J. Health Promot. 2009; 23 (3): 176-181.

[19] Virlogeux, V., Trépo, C. Extrahepatic Manifestations of Chronic Hepatitis B Infection. Curr Hepatology Rep. 2018; 17, 156-165.
[20] European Association for the Study of the Liver. (EASL) clinical practice guidelines: Management of chronic hepatitis B virus infection. J. Hepatol. 2012; 57 (1): 167-185.

[21] Evens A, Jovanovic B, Su Y, Raisch D, Ganger D, Belknap $S$, et al. Rituximab-associated hepatitis B virus (HBV) reactivation in lymphoproliferative diseases: meta-analysis and examination of FDA safety reports. Ann Oncol. 2011; 22 (5):1170-1180.

[22] Yoo J, Cho E, Cho Y, Lee M, Lee D, Cho Y, et al. Efficacy of antiviral prophylaxis in HBsAg-negative, anti-HBc positive patients undergoing hematopoietic stem cell transplantation. Liver Int. 2015; 35 (12): 2530-2536.

[23] Aygen B, Demir A, Gümüş M, Karabay O, Kaymakoğlu S, Köksal A, et al. Immunosuppressive therapy and the risk of hepatitis B reactivation: Consensus report. Turk J Gastroenterol. 2018; 29: 259-269.

[24] Tavakolpour S, Alavian S, Sali S. Hepatitis B reactivation during immunosuppressive therapy or cancer chemotherapy, management, and prevention: A Comprehensive review. Hepat Mon. 2016; 16 (4): e35810.

[25] European Association for the Study of the Liver. (EASL) clinical practice guidelines: Management of acute (fulminant) liver failure. J Hepatol. 2017; 66: 1047-1081.

[26] Lampertico P, Maini M, Papatheodoridis G. Optimal management of hepatitis $\mathrm{B}$ virus infection-EASL special conference. J. Hepatol. 2015; 63: 1238-1253.

[27] Papatheodoridis GV. Why do I treat HBeAgnegative chronic hepatitis $\mathrm{B}$ patients with nucleos(t)ide analogues? Liver Int. 2013; 33 (1):151-156.

[28]Gane E, Deray G, Liaw Y, Lim S, Lai C, Rasenack J, et al. Telbivudine improves renal function in patients with chronic hepatitis B. Gastroenterology. 2014; 146: 138-146.

[29]Lee M, Oh S, Lee H, Yeum T, Lee J, Yu S, et al. Telbivudine protects renal function in patients with chronic hepatitis B infection in conjunction with adefovir-based combination therapy. J Viral Hepat. 2014; 21: 873-881.

[30]Pipili C, Cholongitas E, Papatheodoridis G. Review article: Nucleos(t)ide analogues in patients with chronic hepatitis B virus infection and chronic kidney disease. Aliment Pharmacol Ther. 2014; 39: 35-46.

[31] Hall A, Hendry B, Nitsch D, Connolly J. Tenofovir-associated kidney toxicity in HIVinfected patients: A review of the evidence. Am J Kidney Dis. 2011; 57: 773-780.

[32] Spradling P, Richardson J, Buchacz K, Moorman A, Brooks J, Investigators HIVOS: Prevalence of chronic hepatitis B virus infection among patients in the HIV Outpatient Study, 1996-2007. J. Viral Hepat 2010; 17 (12): 87986. 
[33] Zhou K, Terrault N. Management of hepatitis $\mathrm{B}$ in special populations. Best Pract Res Clin Gastroenterol. 2017; 31: 311-320

[34] Terrault N, Bzowej N, Chang K, Hwang J, Jonas M, Murad M. American Association for the Study of Liver Diseases. (AASLD) guidelines for treatment of chronic hepatitis B. Hepatology. 2016; 63: 261-283.

[35] Bortolotti F, Guido M, Bartolacci S, Cadrobbi P, Crivellaro C, Noventa F, et al. Chronic hepatitis $B$ in children after e antigen seroclearance: Final report of a 29-year longitudinal study. Hepatology. 2006; 43 (3): 556-562.

[36]Sokal E, Paganelli M, Wirth S, Socha P, Vajro $\mathrm{P}$, Lacaille F, et al. Management of chronic hepatitis B in childhood: ESPGHAN clinical practice guidelines: consensus of an expert panel on behalf of the European Society of Pediatric Gastroenterology, Hepatology and Nut rition. J. Hepatol. 2013; 59 (4): 814-829.

[37] Wirth S, Zhang H, Hardikar W, Schwarz K, Sokal E, Yang W, et al. Efficacy and safety of peginterferon alfa-2a (40KD) in children with chronic hepatitis B: the PEG-B-ACTIVE Study. Hepatology. 2018; 68 (5): 1681-1694.
[38] Jonas M, Chang M, Sokal E, Schwarz K, Kelly D, Kim KM, et al. Randomized, controlled trial of entecavir versus placebo in children with hepatitis B envelope antigen-positive chronic hepatitis B. Hepatology. 2016; 63 (2): 377-387.

[39] Sokal E, Bourgois A, Stephenne X, Silveira T, Porta G, Gardovska D, et al. Peginterferon alfa2a plus ribavirin for chronic hepatitis $\mathrm{C}$ virus infection in children and adolescents. J. Hepatol. 2010; 52 (6): 827-831.

[40] Dahiya P, Kamal R, Sharma V, Kaur S. "Hepatitis" - Prevention and management in dental practice. J. of Education and Health Promotion. 2015; 4: doi: 10.4103/2277-9531. 157188

[41] Coates E, Brennan D, Logan R, Goss A, Scopacasa B, Spencer A, Gorkic E. Hepatitis C infection and associated oral health problems. Aust Dent J. 2000; 45 (2):108-114.

[42]Fry D. Occupational blood-borne diseases in surgery. Am J. Surg. 2005; 190 (2): 249-254.

[43]Withers A. Hepatitis: A review of the disease and significance to dentistry. J Periodontol. 1980; 51: 162-166. 